\title{
Vitamin D Supplementation in the Pediatric Rheumatology Clinic
}

\author{
Emily von Scheven • Jon M. Burnham
}

Published online: 8 January 2011

(C) The Author(s) 2011. This article is published with open access at Springerlink.com

\begin{abstract}
Vitamin D is capturing the attention of healthy and chronically ill populations for its potential skeletal and nonskeletal benefits. New information suggesting a role in immune modulation has led to a surge of interest among rheumatologists. Although the epidemiologic data are limited, it appears that many children with rheumatic conditions are at risk of vitamin D deficiency. However, understanding this phenomenon requires an appreciation for how vitamin D status is assessed, and options for supplementation. Although a "more-is-better" attitude is tempting when considering the medicinal effects of a nutritional supplement, we suggest a cautious approach and suggest that further studies are needed to clarify the potential benefits and risks among children with rheumatic conditions.
\end{abstract}

Keywords Vitamin D · Child · Juvenile arthritis · Systemic lupus erythematosus

\section{Introduction}

For many years, vitamin D was considered simply another fatsoluble vitamin with important skeletal effects. However,

E. von Scheven $(\bowtie)$

Pediatric Rheumatology, University of California, San Francisco,

Box 0107, 533 Parnassus Avenue, Room U-126,

San Francisco, CA 94143, USA

e-mail: evonsche@peds.ucsf.edu

J. M. Burnham

Division of Pediatric Rheumatology,

The Children's Hospital of Philadelphia,

Room 1579 CHOP North,

Philadelphia, PA 19010, USA

e-mail: burnhams@email.chop.edu epidemiologic studies suggesting more widespread health effects have led to a surge of interest in this vitamin. Examples of newly identified health benefits include the prevention of cancer, reduction of risk of myocardial ischemia, and prevention and regulation of autoimmune disease. This has led to a flood of studies examining the molecular interactions of vitamin D and its role in disease, and clinical trials examining the benefits of supplementation. Unfortunately, despite these efforts, the suggested form of vitamin for assessing nutritional status, the optimal level for health, and the recommended dose for supplementation all remain unclear. Among pediatricians, the perceived potential benefit of vitamin $\mathrm{D}$ for maximizing peak bone mass and preventing osteoporosis combined with a strong interest among providers, patients, and parents to use "safe" medications has led to an eagerness to supplement children with rheumatic conditions with vitamin D. In this report, we describe the current understanding of the biologic mechanisms of vitamin $\mathrm{D}$ with a focus on their relevance to children with rheumatic diseases. Additionally, we provide a summary of the clinical trial experience to date for vitamin $\mathrm{D}$ supplementation. The emerging story will demonstrate the importance of this nutrient and the need for future studies. Unfortunately, due to limited data available at this time, particularly in children with chronic illnesses, no consensus exists about how best to approach this important phenomenon in the pediatric rheumatology clinic.

\section{Biologic Effects of Vitamin D}

Vitamin D3 may be ingested from dietary sources such as fortified milk or oily fish, or derived from the conversion of 7-dehydrocholesterol to previtamin-D3 by solar UVB radiation. Vitamin D3 is transported to the liver, where it 
is converted to 25 -hydroxyvitamin $\mathrm{D}(25[\mathrm{OH}] \mathrm{D})$, the best single determinant of vitamin D status [1,2]. Production of the active form of vitamin $\mathrm{D}, 1,25$-dihydroxyvitamin $\mathrm{D}$ $\left(1,25[\mathrm{OH}]_{2} \mathrm{D}\right)$ via the $25(\mathrm{OH}) \mathrm{D}-1 \alpha$-hydroxylase (CYP27B1) enzyme in the proximal tubular epithelial cells of the kidney is tightly regulated by serum parathyroid hormone (PTH), calcium, and phosphorous concentrations [1].

$1,25(\mathrm{OH})_{2} \mathrm{D}$ impacts gene transcription by binding to the vitamin D receptor (VDR). The VDR forms a heterodimer with the retinoid $\mathrm{X}$ receptor in the cytoplasm, which translocates into the nucleus and binds to vitamin D response elements in vitamin D-responsive genes. The classic endocrine actions of $1,25(\mathrm{OH})_{2} \mathrm{D}$ are to increase intestinal calcium and phosphate absorption and to induce expression of receptor activator of nuclear factor- $\mathrm{kB}$ ligand in osteoblasts. The latter function results in the maturation of osteoclasts and increased bone resorption, which allows for release of calcium into the bloodstream [3]. Recent attention has focused on local intracrine or paracrine effects of vitamin D whereby $25(\mathrm{OH}) \mathrm{D}$ is converted locally into $1,25(\mathrm{OH})_{2} \mathrm{D}$ in immune cells, pancreatic $\beta$ cells, and vascular smooth muscle cells, for example. Local production of $1,25(\mathrm{OH})_{2} \mathrm{D}$ may be adversely impacted by $25(\mathrm{OH})$ $\mathrm{D}$ deficiency [4].

\section{Effects of Vitamin D on Bone and Muscle}

Extreme 25(OH)D deficiency causes rickets in growing children and osteomalacia after skeletal maturation [5]. Rickets causes pain, bowing and splaying of long bones, and infections [5]. Vitamin D supplementation in adults results in a lowering of fracture risk, likely via suppression of PTH-induced excess bone remodeling, improvements in bone mass, and prevention of falls [6].

Some supplementation studies in girls suggest a role for vitamin $\mathrm{D}$ to maximize bone mass, muscle mass, and muscle function. In one study of 179 Lebanese girls 10 to 17 years of age, vitamin D3 supplementation was provided for a period of 1 year [7]. Compared with placebo, lowdose $(1,400-\mathrm{IU} / \mathrm{wk})$ supplementation improved lumbar spine bone density. Low- and high-dose (14,000-IU/wk) regimens improved lean mass and bone mineral content in the trochanteric region of the hip. These improvements were limited to girls prior to menarche. In a randomized clinical trial in Finland, 228 girls were randomly assigned to placebo, $200 \mathrm{IU} / \mathrm{d}$, or vitamin $\mathrm{D} 3,400 \mathrm{IU} / \mathrm{d}$, for 1 year [8]. Positive effects of supplementation on bone mineral content were noted in the femur (low- and higher-dose groups) and the spine (higher-dose group), in which the effects were more pronounced in mid-pubertal girls. Urine deoxypyridinoline, a bone resorption marker, was reduced significantly. Limitations of this study included restriction of the analysis to those who were adherent to the supplementation regimen, and given the low doses of vitamin tested, the effects on serum $25(\mathrm{OH}) \mathrm{D}$ concentrations were modest. A recent study of 73 postmenarchal girls 12 to 14 years of age assessed bone mass and musculoskeletal function [9]. Participants had 25(OH)D concentrations less than $15 \mathrm{ng} / \mathrm{mL}$ and were randomly assigned to placebo or four doses of vitamin D2, 150,000 IU every 3 months. No change was observed in bone mass, but muscle function improved significantly, particularly among those with the lowest baseline $25(\mathrm{OH}) \mathrm{D}$ concentrations. Together, these studies suggest a potential benefit on musculoskeletal outcomes, particularly in girls prior to menarche.

\section{Effects of Vitamin D on Glucose Homeostasis}

Vitamin D impacts insulin secretion and insulin sensitivity. Deficiency in rats caused lower insulin secretion by pancreatic islet cells [10]. $1,25(\mathrm{OH})_{2} \mathrm{D}$ may increase insulin production by modulating $\beta$-cell growth and increasing cytosolic calcium concentrations in $\beta$ cells, which may increase exocytosis of insulin, glycogenolysis, and the conversion of proinsulin to insulin [11]. The mechanism by which vitamin D deficiency impacts insulin resistance is not fully understood but may be mediated indirectly by vitamin $\mathrm{D}$ effects on inflammation or secondary hyperparathyroidism [11]. In nondiabetic adults, lower 25(OH)D levels were predictive of lower insulin sensitivity after adjustment for sex, age, race, blood pressure, and body mass index [12]. These data likely translate to the pediatric population. In 3577 nondiabetic American adolescents enrolled in the National Health and Nutrition Examination Survey (2001-2004), those with the lowest 25(OH)D concentrations had a significantly greater risk of fasting hyperglycemia and the metabolic syndrome [13]. In African American adolescent females, a 25(OH)D concentration of less than $15 \mathrm{ng} / \mathrm{mL}$ was associated with significantly greater insulin resistance after an oral glucose challenge [14]. To date, however, clinical trials of vitamin D supplementation in adults with normal glucose tolerance have not consistently shown benefits on fasting glucose or diabetes risk [15]. However, one study showed a lower increase in fasting glucose concentrations in adults with impaired glucose tolerance prescribed vitamin D3 (700 IU/ day) and calcium for 3 years. To date, the role of vitamin D supplementation in glucose homeostasis in children has not been systematically evaluated.

\section{Cardiovascular Effects of Vitamin D}

Vitamin D may exert protective cardiovascular effects via pleiotropic actions, including — but not limited to - regulation 
of the renin-angiotensin system, inhibition of vascular smooth muscle proliferation and function, reduction of inflammation and insulin resistance, and promotion of anticoagulant properties of monocytes [15]. In adolescents, a 25(OH)D concentration of less than $15 \mathrm{ng} / \mathrm{mL}$ was associated with a greater than twofold risk of hypertension [13]. This effect was independent of age, sex, race, physical activity, and body mass index. In some observational studies, vitamin D deficiency has been associated with incident cardiovascular disease [16, 17] and death from cardiovascular events such as myocardial infarction and stroke [18, 19]. Vitamin D supplementation trials in adults suggest a potential benefit, particularly systolic blood pressure, but have not yet demonstrated a significant benefit with regard to cardiovascular events [15].

\section{Immunologic Effects of Vitamin D}

Vitamin D is a recognized regulator of immune function (Table 1). By enhancing macrophage production of antimicrobial peptides, vitamin D may play a critical role in the clearance of mycobacterial infections [20]. Conversely, vitamin D suppresses proinflammatory properties of dendritic cells (DCs) [21], antigen-presenting cells that stimulate immune responses, prevent autoimmunity, and link the innate and adaptive immune response. These immunomodulating effects have potential implications for a variety of autoimmune conditions, including - but not limited to-systemic lupus erythematosus (SLE), juvenile dermatomyositis, juvenile idiopathic arthritis, and multiple sclerosis [22].

Although there are specific effects of vitamin D on T cells, vitamin D effects on myeloid DCs likely drive changes in Tcell activity [23••]. VDR agonists decrease DC expression of CD40, CD80, CD86, and interleukin (IL)-12 and increase IL-10 expression, indicating that the main effects of vitamin $\mathrm{D}$ are to decrease T-cell stimulation and increase immune tolerance. 1,25(OH)D significantly decreased interferon- $\alpha$ and granulocyte-macrophage colony-stimulating factor-

Table 1 Immunologic effects of vitamin D that may influence autoimmune diseases

\begin{tabular}{ll}
\hline Cell type & Vitamin D effect \\
\hline Dendritic cells & $\downarrow$ CD40, CD80, CD86, IL-12 expression \\
& $\uparrow$ IL-10 expression \\
& $\uparrow$ Chemokines that attract Tregs \\
& $\downarrow$ Th1 and Th17 action (possible) \\
T cells & $\uparrow$ Tregs \\
& $\downarrow$ Proliferation and differentiation \\
B cells & $\uparrow$ Apoptosis \\
\end{tabular}

IL_interleukin; Th1—T-helper type 1; Th17-T-helper type 17; Tregregulatory $\mathrm{T}$ cell induced expression of DC maturation and activation markers. Reduced expression of IL-12 by DCs with VDR agonists suppresses T-helper type 1 (Th1) development [24], while greater IL-10 expression promotes regulatory T-cell (Treg) development [25]. In an experimental colitis model, amelioration of disease by vitamin $\mathrm{D}$ was thought to be due to induction of Tregs and reductions in IL-12, IL-23, and IL6 [26]. IL-12 inhibition reduces Th1 development, while IL6 and IL-23 inhibition reduce Th17 development. VDR agonists can modulate T-cell function by altering DC chemokine expression. One VDR agonist, BXL-219, inhibited effector T-cell recruitment in a type 1 diabetes model by inhibiting proinflammatory chemokine production [27]. Immature myeloid DCs produce CCL17 and CCL22, chemokines that attract cells expressing CCR4, a receptor that is present on Tregs. Myeloid DC production of CCL22 is augmented by VDR agonists [24]. In the epidermis, active vitamin D produced by DCs in response to sunlight upregulates T-cell expression of CCR10. This chemokine receptor binds CCL27, which directs epidermal migration. It is hypothesized that Tregs migrate to the epidermis to counteract inflammation associated with sun exposure.

Vitamin D has been found to regulate B-cell development, survival, and function. An effect of vitamin D is supported by the upregulation of the VDR with B-cell stimulation or addition of $1,25(\mathrm{OH})_{2} \mathrm{D}$, and the ability of $\mathrm{B}$ cells to metabolize $25(\mathrm{OH}) \mathrm{D}$ into $1,25(\mathrm{OH})_{2} \mathrm{D} \quad[28]$. $1,25(\mathrm{OH})_{2} \mathrm{D}$ significantly inhibited B-cell proliferation when stimulated with anti-IgM, anti-CD40, and IL-21 and enhanced their apoptosis. Plasma cell differentiation, post-switch memory B-cell differentiation, and immunoglobulin secretion were inhibited by $1,25(\mathrm{OH})_{2} \mathrm{D}$. Together, these data suggest that $1,25(\mathrm{OH})_{2} \mathrm{D}$ reduces B-cell hyperactivation.

\section{Interrelationship of Vitamin D and Cancer}

An inverse relationship between sun exposure and mortality among patients with colon and prostate cancer first suggested the potential beneficial effect of vitamin D in cancer [29]. Many genes that influence proliferation, invasiveness, angiogenesis, metastatic potential, differentiation, and apoptosis have been demonstrated to be under the influence of vitamin D [30] However, evidence also supports a potential negative effect of vitamin D on cancer, demonstrating the need for further studies in this area.

\section{Potential Importance of Vitamin D in Pediatric Autoimmune Diseases}

Vitamin D represents an appealing therapy in pediatric rheumatic diseases. Its myriad effects may both minimize 
disease-related comorbidities such as bone fragility [31], accelerated cardiovascular disease, and infections and attenuate the immune hyperactivation that is characteristic of conditions such as pediatric SLE [32•] and multiple sclerosis. In pediatric SLE patients with $25(\mathrm{OH}) \mathrm{D}$ less than $20 \mathrm{ng} / \mathrm{mL}$, the SLE Disease Activity Index scores were significantly higher. This finding in children was replicated in a more recent study conducted in a larger, multicenter cohort of 198 adults with SLE [33]. Additionally, lower 25 $(\mathrm{OH}) \mathrm{D}$ concentrations were associated with a greater relapse rate in pediatric multiple sclerosis [34]. Randomized clinical trials in pediatric rheumatic diseases will be required to determine whether vitamin $\mathrm{D}$ supplementation diminishes disease activity and damage.

\section{Defining Optimal Vitamin D Status}

Although $1,25(\mathrm{OH})_{2} \mathrm{D}$ is the active form of vitamin $\mathrm{D}$, it has a very short half-life, and in the early stages of vitamin $\mathrm{D}$ deficiency, while $25(\mathrm{OH}) \mathrm{D}$ falls, $1,25(\mathrm{OH})_{2} \mathrm{D}$ can remain normal or even rise. Thus, $25(\mathrm{OH}) \mathrm{D}$ is the usual recommended vitamin D metabolite for assessing total stores [35••]. However, interpretation of the vitamin D level and defining adequacy remain controversial. For many years, a "normal" vitamin D level was defined as that level necessary to maintain a normal PTH. However, emerging data suggesting more pleiotropic effects of vitamin D and a focus on maintaining bone health have led to the suggestion that ideal vitamin D levels may be higher than originally suggested. Today, most reference laboratories still provide a wide range for "normal," reflecting the now-recognized hypovitaminosis D commonly seen in otherwise-well individuals and the fact that the definition of "sufficiency" remains controversial. However, most experts today define vitamin D deficiency as a $25(\mathrm{OH}) \mathrm{D}$ level less than $20 \mathrm{ng} /$ $\mathrm{mL}(50 \mathrm{nmol} / \mathrm{L})$, insufficiency as a level between 21 and $29 \mathrm{ng} / \mathrm{mL}(52-72 \mathrm{nmol} / \mathrm{L})$, and optimal levels greater than $30 \mathrm{ng} / \mathrm{mL}(70 \mathrm{nmol} / \mathrm{L})$ [36-38]. Whether these recommendations apply to children and adolescents remains unclear. Furthermore, it is not yet clear whether the same definition of vitamin D sufficiency applies to children with rheumatic disease as to those who are otherwise healthy.

\section{Vitamin D Deficiency: Identifying At-Risk Populations}

Several features are now well-recognized from epidemiologic studies as important risk factors for vitamin D deficiency in children. Due to the relatively low concentrations of vitamin D in most foods, sun exposure historically has been the greatest source of vitamin D for humans. Thus, anything that reduces exposure to UVB radiation may contribute to low vitamin $\mathrm{D}$ production. This includes living at higher latitudes, increased time spent indoors, use of sunscreen, and darker skin pigmentation [1, 2, 39]. A study of obese adolescents demonstrated a significant correlation between reduced 25(OH)D levels and obesity as assessed by abdominal CT measurements of visceral fat [40]. Given the rise in obesity, this association suggests an important risk factor for vitamin D status and possible pathways for the action of vitamin $\mathrm{D}$ on health.

Although vitamin D insufficiency has been demonstrated in several adult studies of rheumatic disease patients, studies in children are limited. Observed reductions in vitamin D levels in these patients may result from the same risk factors observed in otherwise-healthy individuals, or from direct effects of the disease and its associated treatment. In a study of children with diverse rheumatic diseases, low vitamin D levels were observed in juvenile idiopathic arthritis, SLE, and juvenile dermatomyositis [41]. However, in a study focused on children with juvenile rheumatoid arthritis, 25(OH)D levels were actually higher in the children with the oligoarticular subtype of juvenile idiopathic arthritis [42]. One challenge in interpreting the results of these studies is the background prevalence of vitamin $\mathrm{D}$ deficiency among healthy individuals, as the mean $25(\mathrm{OH}) \mathrm{D}$ level in these healthy children was also low $(22.0 \pm 8.5 \mathrm{ng} / \mathrm{mL})$. Very few studies of vitamin D status have been conducted in childhood SLE, but the co-author of this article (Dr. Burnham) reported in a cohort of 38 children with SLE that severe vitamin D deficiency (25 $[\mathrm{OH}] \mathrm{D}<10 \mathrm{ng} / \mathrm{mL}$ ) was more frequently seen in those with SLE than in healthy controls $(36.8 \%$ vs $9.2 \%)$, and there was a strong association with obesity [32•]. This is similar to that reported in adult SLE cohorts [43••]. Furthermore, reduced vitamin D levels appear to be a very common problem in SLE, with a large Canadian study of women with SLE demonstrating suboptimal levels of $25(\mathrm{OH}) \mathrm{D}$ in $66 \%$ and deficiency in $17.9 \%$ of women [44].

Although more epidemiologic studies are needed to help us better understand which children with rheumatic diseases are at greatest risk of developing vitamin $\mathrm{D}$ deficiency, the compelling data pointing to a role for vitamin $\mathrm{D}$ in immune regulation suggest that special attention should be paid to these at-risk populations.

\section{Approach to Vitamin D Supplementation in Children with Rheumatic Conditions}

The goal of vitamin D supplementation is to reverse 25 $(\mathrm{OH}) \mathrm{D}$ deficiency or to maintain optimal $25(\mathrm{OH}) \mathrm{D}$ concentrations. In 2008, the American Academy of Pediatrics increased the recommended minimum daily intake of vitamin D from 200 to 400 IU for infants, children, and 
adolescents and stated that serum 25(OH)D levels should be maintained at greater than $20 \mathrm{ng} / \mathrm{mL}$ [35••]. However, observational data examining skeletal and nonskeletal outcomes suggest that a $25(\mathrm{OH}) \mathrm{D}$ level of $30 \mathrm{ng} / \mathrm{mL}$ should be the minimum cut point for vitamin D sufficiency [45]. Recently released Institute of Medicine guidelines focused on the recommended intake to ensure adequate bone health in otherwise-healthy individuals and suggested $600 \mathrm{IU} / \mathrm{d}$ for healthy children [46••]. This study also highlighted the concern that excessive intake of vitamin D may be harmful and that further studies are needed to help us better understand the tolerable upper limit of intake to prevent toxicity. All supplementation strategies should be designed to achieve a target $25(\mathrm{OH}) \mathrm{D}$ concentration.

Vitamin D may be supplemented in active or inactive forms. Supplementation with active vitamin $\mathrm{D}\left(1,25[\mathrm{OH}]_{2} \mathrm{D}\right)$ carries a risk of hypercalcemia [47] and is generally reserved for individuals with chronic kidney disease because the kidney is a main site at which $25(\mathrm{OH}) \mathrm{D}$ is converted to 1,25 $(\mathrm{OH})_{2} \mathrm{D}$. Among those individuals able to convert $25(\mathrm{OH}) \mathrm{D}$ to $1,25(\mathrm{OH})_{2} \mathrm{D}$, supplementation with vitamin $\mathrm{D} 2$ (ergocalciferol) or $\mathrm{D} 3$ (cholecalciferol) is preferred, as the 25(OH)D is the required substrate for conversion to $1,25(\mathrm{OH})_{2} \mathrm{D}$ at the cellular level. Vitamin D2 does not have the long-term potency of D3. When adults were supplemented with a single 50,000-IU dose of vitamin D2 or D3, 25(OH)D levels increased equivalent amounts in the first 3 days after supplementation. However, by 2 weeks, D2 levels were not greater than presupplementation levels. In contrast, D3 levels were still greater than baseline at 28 days after supplementation [48]. Similarly, supplementation with 4,000 IU of D3 for 14 days yielded significantly greater increases in $25(\mathrm{OH})$ $\mathrm{D}$ than those supplemented with an equivalent dose of D2 [49]. In adults, each 1,000 IU of vitamin D3 per day increased 25(OH)D levels by 7 to $10 \mathrm{ng} / \mathrm{mL}$ [50].

Recent studies demonstrated the safety and efficacy of vitamin D3 supplementation in pediatric populations. Children with neuromuscular disorders received vitamin D3, $1,000 \mathrm{IU} / \mathrm{d}$ for $5 \mathrm{~d} / \mathrm{wk}$, or no supplementation for 10 weeks [51]. 25(OH)D levels increased by about $5 \mathrm{ng} / \mathrm{mL}$ in the supplementation group and decreased by $2 \mathrm{ng} / \mathrm{mL}$ in the untreated group. Weekly supplementation of 14,000 IU of vitamin D3 for 8 weeks in vitamin D-replete Lebanese adolescents resulted in a significant increase in $25(\mathrm{OH}) \mathrm{D}$ concentrations compared with placebo. None of the participants developed vitamin D toxicity, defined as elevations of serum calcium and $25(\mathrm{OH}) \mathrm{D}$ in the same individual. In a 1-year study of Lebanese children and adolescents 10 to 17 years of age, participants received vitamin D3 at $0,1,400$, or 14,000 IU/wk [7]. The mean baseline $25(\mathrm{OH}) \mathrm{D}$ was $14 \mathrm{ng} / \mathrm{mL}$. After supplementation, $25(\mathrm{OH}) \mathrm{D}$ levels in the three groups were 16,17 , and $38 \mathrm{ng} /$ $\mathrm{mL}$ in girls and 17,20 , and $35 \mathrm{ng} / \mathrm{mL}$ in boys, respectively.
No hypercalcemia was observed in those receiving vitamin D3. Three individuals in the high-dose group experienced serum 25(OH)D levels up to $195 \mathrm{ng} / \mathrm{mL}$, but concomitant hypercalcemia was not observed. None of the participants in the latter two studies developed vitamin D toxicity, defined as elevations of serum calcium and $25(\mathrm{OH}) \mathrm{D}$ in the same individual. Thus, vitamin D supplementation of up to 2,000 IU/d appears to be safe and well-tolerated in daily or weekly dosing regimens.

\section{Looking to the Future}

Current interest in the pleiotropic effects of vitamin D and the potentially important therapeutic benefits for health is anticipated to spawn continued studies in this area. The challenges to date in demonstrating efficacy of nutritional supplements using traditional clinical trial designs are a legitimate concern that must be addressed to clarify the best approach to vitamin D supplementation. Further research is needed to elucidate the optimal level for health across the age spectrum, to develop safe and effective supplementation strategies, and to determine the highest safe level for vitamin D. Through future studies, new roles for vitamin $\mathrm{D}$ in health and disease are likely to emerge, resulting in additional indications for monitoring and supplementation.

\section{Conclusions}

Current evidence suggests that many children and adolescents are affected by vitamin D deficiency, and those with rheumatic diseases are at particular risk of the negative consequences of suboptimal vitamin D stores. In addition to the skeletal concerns for patients with rheumatic conditions, maintaining optimal vitamin D stores may actually serve an important role for controlling the underlying immune hyperactivation. Thus, it is recommended that these patients be screened and counseled on the importance of ensuring adequate intake. In the absence of specific guidelines for children with rheumatic conditions, the American Academy of Pediatrics guidelines provide useful minimum dosing regimens for children. However, it is important to recognize that further studies are needed to determine if the beneficial effects in at-risk populations are comparable with those in healthy populations.

Acknowledgments Dr. Burnham has received research support from The Children's Hospital of Philadelphia Research Institute and the National Institute of Allergy and Infectious Diseases.

Disclosure No potential conflicts of interest relevant to this article were reported. 
Open Access This article is distributed under the terms of the Creative Commons Attribution Noncommercial License which permits any noncommercial use, distribution, and reproduction in any medium, provided the original author(s) and source are credited.

\section{References}

Papers of particular interest, published recently, have been highlighted as:

- Of importance

•• Of major importance

1. Holick, M.F., Vitamin D deficiency. N Engl J Med, 2007. 357(3): p. 266-81.

2. Chen, T.C., et al., Factors that influence the cutaneous synthesis and dietary sources of vitamin D. Arch Biochem Biophys, 2007. 460(2): p. 213-7.

3. Heaney, R.P., Vitamin D endocrine physiology. J Bone Miner Res, 2007. 22 Suppl 2: p. V25-7.

4. Adams, J.S. and M. Hewison, Update in vitamin D. J Clin Endocrinol Metab. 95(2): p. 471-8.

5. Wharton, B. and N. Bishop, Rickets. Lancet, 2003. 362(9393): p. 1389-400.

6. Bischoff-Ferrari, H., Vitamin D: what is an adequate vitamin D level and how much supplementation is necessary? Best Pract Res Clin Rheumatol, 2009. 23(6): p. 789-95.

7. El-Hajj Fuleihan, G., et al., Effect of vitamin D replacement on musculoskeletal parameters in school children: a randomized controlled trial. J Clin Endocrinol Metab, 2006. 91(2): p. 405-12.

8. Viljakainen, H.T., et al., A positive dose-response effect of vitamin D supplementation on site-specific bone mineral augmentation in adolescent girls: a double-blinded randomized placebo-controlled 1-year intervention. J Bone Miner Res, 2006. 21(6): p. 836-44.

9. Ward, K.A., et al., A randomized, controlled trial of vitamin D supplementation upon musculoskeletal health in postmenarchal females. J Clin Endocrinol Metab. 95(10): p. 4643-51.

10. Norman, A.W., et al., Vitamin D deficiency inhibits pancreatic secretion of insulin. Science, 1980. 209(4458): p. 823-5.

11. Takiishi, T., et al., Vitamin D and diabetes. Endocrinol Metab Clin North Am. 39(2): p. 419-46, table of contents.

12. Chiu, K.C., et al., Hypovitaminosis D is associated with insulin resistance and beta cell dysfunction. Am J Clin Nutr, 2004. 79(5): p. 820-5.

13. Reis, J.P., et al., Vitamin D status and cardiometabolic risk factors in the United States adolescent population. Pediatrics, 2009. 124 (3): p. e371-9.

14. Ashraf, A., et al., Threshold for effects of vitamin D deficiency on glucose metabolism in obese female African-American adolescents. J Clin Endocrinol Metab, 2009. 94(9): p. 3200-6.

15. Pittas, A.G., et al., Systematic review: vitamin D and cardiometabolic outcomes. Ann Intern Med. 152(5): p. 307-14.

16. Giovannucci, E., et al., 25-hydroxyvitamin D and risk of myocardial infarction in men: a prospective study. Arch Intern Med, 2008. 168(11): p. 1174-80.

17. Wang, T.J., et al., Vitamin D deficiency and risk of cardiovascular disease. Circulation, 2008. 117(4): p. 503-11.

18. Dobnig, H., et al., Independent association of low serum 25hydroxyvitamin D and 1,25-dihydroxyvitamin D levels with allcause and cardiovascular mortality. Arch Intern Med, 2008. 168(12): p. $1340-9$.

19. Kilkkinen, A., et al., Vitamin D status and the risk of cardiovascular disease death. Am J Epidemiol, 2009. 170(8): p. 1032-9.
20. Liu, P.T., et al., Toll-like receptor triggering of a vitamin Dmediated human antimicrobial response. Science, 2006. 311 (5768): p. 1770-3.

21. Gauzzi, M.C., et al., Suppressive effect of 1alpha,25-dihydroxyvitamin D3 on type I IFN-mediated monocyte differentiation into dendritic cells: impairment of functional activities and chemotaxis. J Immunol, 2005. 174(1): p. 270-6.

22. Pelajo, C.F., J.M. Lopez-Benitez, and L.C. Miller, Vitamin D and autoimmune rheumatologic disorders. Autoimmun Rev. 9 (7): p. $507-10$.

23. - Adams, J.S. and M. Hewison, Unexpected actions of vitamin D: new perspectives on the regulation of innate and adaptive immunity. Nat Clin Pract Endocrinol Metab, 2008. 4(2): p. 80-90. This is an excellent review of the potential mechanisms underlying a role for vitamin $D$ in autoimmune diseases.

24. Penna, G., et al., 1,25-Dihydroxyvitamin D3 selectively modulates tolerogenic properties in myeloid but not plasmacytoid dendritic cells. J Immunol, 2007. 178(1): p. 145-53.

25. Adorini, L., N. Giarratana, and G. Penna, Pharmacological induction of tolerogenic dendritic cells and regulatory $\mathrm{T}$ cells. Semin Immunol, 2004. 16(2): p. 127-34.

26. Daniel, C., et al., Immune modulatory treatment of trinitrobenzene sulfonic acid colitis with calcitriol is associated with a change of a $\mathrm{T}$ helper (Th) $1 /$ Th17 to a Th2 and regulatory T cell profile. J Pharmacol Exp Ther, 2008. 324(1): p. 23-33.

27. Giarratana, N., et al., A vitamin D analog down-regulates proinflammatory chemokine production by pancreatic islets inhibiting $\mathrm{T}$ cell recruitment and type 1 diabetes development. J Immunol, 2004. 173(4): p. 2280-7.

28. Chen, S., et al., Modulatory effects of 1,25-dihydroxyvitamin D3 on human B cell differentiation. J Immunol, 2007. 179(3): p. 1634-47.

29. Garland, C.F. and F.C. Garland, Do sunlight and vitamin D reduce the likelihood of colon cancer? Int J Epidemiol, 1980. 9(3): p. $227-31$

30. Toner, C.D., C.D. Davis, and J.A. Milner, The vitamin D and cancer conundrum: aiming at a moving target. J Am Diet Assoc. 110(10): p. 1492-500.

31. Bultink, I.E., et al., Prevalence of and risk factors for low bone mineral density and vertebral fractures in patients with systemic lupus erythematosus. Arthritis Rheum, 2005. 52(7): p. 2044-50.

32. - Wright, T.B., et al., Hypovitaminosis D is associated with greater body mass index and disease activity in pediatric systemic lupus erythematosus. J Pediatr, 2009. 155(2): p. 260-5. This was an observational study characterizing the vitamin D status of children with SLE and the interaction with obesity.

33. Ben-Zvi, I., et al., The impact of vitamin D on dendritic cell function in patients with systemic lupus erythematosus. PLoS One. 5(2): p. e9193.

34. Mowry, E.M., et al., Vitamin D status is associated with relapse rate in pediatric-onset multiple sclerosis. Ann Neurol. 67(5): p. 618-24.

35. •- Wagner, C.L. and F.R. Greer, Prevention of rickets and vitamin D deficiency in infants, children, and adolescents. Pediatrics, 2008. 122(5): p. 1142-52. This article lists the American Academy of Pediatrics' recommendations for vitamin D intake in children.

36. Bischoff-Ferrari, H.A., et al., Estimation of optimal serum concentrations of 25-hydroxyvitamin D for multiple health outcomes. Am J Clin Nutr, 2006. 84(1): p. 18-28.

37. Holick, M.F., High prevalence of vitamin D inadequacy and implications for health. Mayo Clin Proc, 2006. 81(3): p. 353-73.

38. Malabanan, A., I.E. Veronikis, and M.F. Holick, Redefining vitamin D insufficiency. Lancet, 1998. 351(9105): p. 805-6.

39. Holick, M.F. and T.C. Chen, Vitamin D deficiency: a worldwide problem with health consequences. Am J Clin Nutr, 2008. 87(4): p. $1080 \mathrm{~S}-6 \mathrm{~S}$.

40. Lenders, C.M., et al., Relation of body fat indexes to vitamin D status and deficiency among obese adolescents. Am J Clin Nutr, 2009. 90(3): p. 459-67. 
41. Reed, A., et al., Abnormalities in serum osteocalcin values in children with chronic rheumatic diseases. J Pediatr, 1990. 116(4): p. 574-80.

42. Pepmueller, P.H., et al., Bone mineralization and bone mineral metabolism in children with juvenile rheumatoid arthritis. Arthritis Rheum, 1996. 39(5): p. 746-57.

43. • Kamen, D.L., Vitamin D in lupus - new kid on the block? Bull NYU Hosp Jt Dis. 2010, 68(3): p. 218-22. This is an insightful article examining the newly emerging role for vitamin $D$.

44. Toloza, S.M., et al., Vitamin D insufficiency in a large female SLE cohort. Lupus. 19(1): p. 13-9.

45. Bischoff-Ferrari, H.A., Optimal serum 25-hydroxyvitamin D levels for multiple health outcomes. Adv Exp Med Biol, 2008. 624: p. 55-71.

46. •- Institute of Medicine of the National Academies: Dietary reference intakes for vitamin D and calcium. Available at http://www.iom.edu/ Reports/2010/Dietary-Reference-Intakes-for-Calcium-and-VitaminD.aspx. This is a new statement by the Institute of Medicine synthesizing recent literature and providing guidelines for dietary intake and target levels of vitamin $D$.

47. Avenell, A., et al., Vitamin D and vitamin D analogues for preventing fractures associated with involutional and post-menopausal osteoporosis. Cochrane Database Syst Rev, 2009(2): p. CD000227.

48. Armas, L.A., B.W. Hollis, and R.P. Heaney, Vitamin D2 is much less effective than vitamin D3 in humans. J Clin Endocrinol Metab, 2004. 89(11): p. 5387-91.

49. Trang, H.M., et al., Evidence that vitamin D3 increases serum 25 hydroxyvitamin D more efficiently than does vitamin D2. Am J Clin Nutr, 1998. 68(4): p. 854-8.

50. Heaney, R.P., et al., Human serum 25-hydroxycholecalciferol response to extended oral dosing with cholecalciferol. Am J Clin Nutr, 2003. 77(1): p. 204-10.

51. Kilpinen-Loisa, P., et al., High-dose vitamin D supplementation in children with cerebral palsy or neuromuscular disorder. Neuropediatrics, 2007. 38(4): p. 167-72. 